\title{
SEMIÁRIDO: UMA PERSPECTIVA GENEALÓGICA
}

\author{
Maria Lucinete Fortunato ${ }^{1}$ \\ Mariana Moreira Neto ${ }^{2}$
}

\section{RESUMO:}

O debate sobre a convivência com o semiárido tem como um dos seus principais pressupostos a sustentabilidade, fundamentada em práticas e alternativas de desenvolvimento harmonioso e integrado das esferas econômica, política e social e no protagonismo dos habitantes do Semiárido. Este debate tem sido referenciado como essencial para a (re)elaboração de relações de poder-saber que, deslocando-se do tradicional discurso da dependência, gestem novas possibilidades para este "território", ancoradas na reflexão de questões como: respeito à diversidade, solidariedade, coletividade, articulação em redes, autogestão etc. Este artigo tece algumas considerações sobre as articulações que temos estabelecido entre as atividades de pesquisa e extensão que desenvolvemos nos últimos anos e os fundamentos teóricometodológico da análise de discurso, na perspectiva de Michel Foucault. Tais atividades buscam apreender a elaboração de visibilidades e dizibilidades das relações de poder/saber das políticas públicas de educação, da educação do campo, do protagonismo de jovens assentados, de mulheres apenadas etc. Interessa-nos problematizar como a elaboração da ideia de convivência com o semiárido institui posições de sujeitos, regimes de verdade e/ou positividade de discursos/saberes, na perspectiva da diversidade e das múltiplas subjetividades. Para tanto, emerge como relevante aprofundar o debate sobre as formas como, nas relações de poder-saber exercitadas e positivadas acerca desse "território", tais questões são enunciadas e se interpõem na instituição da ideia de convivência com o semiárido. Neste sentido, pensamos o Semiárido por meio da utilização e apropriação gestadas por discursos e exercitadas nas relações de poder, através de estratégias e correlações de forças, positivadas nas relações políticas e socioculturais.

Palavras-chave: Discurso, convivência; Semiárido.

\section{SEMIARID: A GENEALOGICAL PERSPECTIVE}

\begin{abstract}
:
The debate on living with the semi-arid region has as one of its main assumptions sustainability, based on practices and alternatives for harmonious and integrated development of the economic, political and social spheres and on the protagonism of the inhabitants of the semi-arid region. This debate has been referred to as essential for the (re) elaboration of power-knowledge relations that, moving from the traditional discourse of dependence, create new possibilities for this "territory", anchored in the reflection of issues such as respect for diversity, solidarity, collectivity, networking, self-management, etc. This article presents some considerations about research and extension activities that we have developed in recent years about these issues, having as a theoretical and methodological basis the analysis of discourse, in the perspective of Michel Foucault. These activities seek to capture the visibility and tellability of the power / knowledge relations of public education policies, rural education, the protagonism of young settlers, women in distress, and so on. We are interested in problematizing how these elaborations establish subject positions, truth regimes and / or positivity of discourses / knowledge about the idea of living with the semi-arid, in the perspective of diversity and multiple subjectivities. In order to do so, it is
\end{abstract}

\footnotetext{
${ }^{1}$ Possui graduação em Bacharelado em História pela Universidade Federal da Paraíba (1986), graduação em Licenciatura Em História pela Universidade Federal da Paraíba (1987), mestrado em Sociologia Rural pela Universidade Federal da Paraíba (1993) e doutorado em História pela Universidade Estadual de Campinas (2000). Atualmente é professor associado IV de nível superior da Universidade Federal de Campina Grande. Tem experiência na área de História, com ênfase em História do Brasil República, atuando principalmente nos seguintes temas: teoria, história, ensino, relações de poder, educação e políticas públicas. Email: mlucinete@uol.com.br.

${ }^{2}$ Possui graduação em Bacharelado em Comunicação Social pela Universidade Federal da Paraíba (1982), mestrado em Sociologia pela Universidade Federal da Paraíba (2000) e doutorado em Sociologia pela Universidade Federal da Paraíba (2009). Atualmente é professor adjunta da Universidade Federal de Campina Grande. Tem experiência na área de Sociologia, com ênfase em Sociologia do Conhecimento, atuando principalmente nos seguintes temas: semiárido, convivência, relações de gênero, assentamentos e educação. Email: moreiramariana@uol.com.br.
} 
relevant to deepen the debate about the ways in which, in the relations of power-knowledge exercised and positivadas about this "territory", such questions are experienced inferring in the conflicts, dissonances and resistances experienced culturally and that interpose in the institution of the idea of living with the semi-arid. In this sense, we think of the Semiarid through the use and appropriation of speeches and exercised in power relations, through strategies and correlations of force, positive in political and sociocultural relations.

Key words: Discourse, coexistence; semiarid.

\section{Introdução}

Desde os anos 1990 começou a ser operacionalizado um deslocamento do discurso do combate à seca para a ideia de convivência, instituindo um redimensionamento de concepções, enunciados e dizeres sobre o que é ser semiárido, como contraponto ao descaso histórico para com a ideia do ser sertão. Compreensão que ganhou projeção quando trabalhadores rurais e urbanos, através de suas organizações $^{3}$, começaram a contestar o modelo de intervenção governamental nas questões relacionadas ao "sertão" e às suas instabilidades climáticas, propondo soluções a partir de outra forma de compreensão da vivência no Semiárido.

A inserção do enunciado da convivência, para designar novas perspectivas de identificação e caracterização do que antes se compreendia como "sertão", deu-se a partir de uma lógica que considera,

(...) que não há mais um nordeste, mas sim, nordestes, e que nessa nova conformação, o Semiárido não pode mais ficar enquanto reduto da pobreza nordestina e brasileira. Ele é potencial, é competitivo, solidário e possui, antes de tudo, uma identidade cultural comum que o faz único (CARVALHO, 2004, p. 21).

Tal compreensão coloca a região semiárida como espaço de tematizações pertinentes sobre o ecossistema caatinga, suas diversidades e sobre as possibilidades de um desenvolvimento sustentável que viabilize a (re)elaboração de novas perspectivas de identificação e caracterização do sertão.

A lógica deste discurso se assenta, ainda, na compreensão de que

(...) a convivência do homem com a semi-aridez pode ser assegurada. O que está faltando, são medidas de política agrária e agrícola, tecnologias apropriadas, gestão democrática e descentralizada dos recursos hídricos e da coisa pública - para corrigir as distorções estruturais seculares, responsáveis pela perpetuação da miséria e da pobreza no meio rural (FÓRUM NORDESTE, 1993, p. 05).

\footnotetext{
${ }^{3}$ Federações estaduais, sindicatos, igrejas, associações, cooperativas de pequenos produtores ONG's de assessoria e apoio, entre outros.

\begin{tabular}{|c|l|l|l|l|}
\hline Qovista Oialectus & Ano 4 & n. 11 & Agosto - Dezembro 2017 & p. $192-204$ \\
\hline
\end{tabular}
}


Na ideia da convivência com o semiárido a sustentabilidade tem se configurado como uma reação social e política à racionalidade econômica que, ao longo dos anos, instituiu discursos e práticas sobre esta região, cartografando-a como economicamente improdutiva e humanamente inviável. De acordo com esta concepção, convivência e sustentabilidade têm sido pensadas como projetos alternativos que poderão se transformar em possibilidades emancipatórias que tenham nas prioridades sociais sua razão primeira, transformando excluídos e marginalizados em cidadãos.

Neste cenário, tensões e contradições constituintes do desenvolvimento das formas de compreender o mundo se apresentam como possibilidades de mudança. É com base nestas questões que temos aprofundado o debate e a troca de experiências entre os diversos saberes e dizeres que gravitam neste palco e que instituem e fomentam as múltiplas forças sociais, políticas e culturais presentes no Semiárido, problematizando a organização e a participação política dos habitantes, a importância de seus protagonismos, a construção de novos saberes e de novas práticas, repensando as formas de produção e reprodução dos discursos e das práticas políticas e culturais, do final do século XX ao início do século XXI.

Esse debate, empreendido por meio de atividades de pesquisa e extensão, se configura como possibilidade de elaboração de visibilidades e dizibilidades acerca das relações de poder/saber que transversalizam e impregnam as políticas públicas de educação, a educação do campo, o protagonismo de jovens assentados etc. Elaborações que instituem posições de sujeitos, regimes de verdade e/ou positividade de discursos/saberes sobre a ideia de convivência com o semiárido na perspectiva da diversidade e das múltiplas subjetividades.

\section{Discussão}

Nas leituras e reflexões teóricas e críticas, bem como nas atividades de pesquisa e extensão que temos desenvolvido (relacionadas às políticas públicas para o Semiárido, ao desenvolvimento sustentável, à autonomia e à questão da convivência com o semiárido, entre outros), verificamos que a compreensão da convivência se anuncia como elemento fundante de uma prática política que envolve todas as dimensões da vida e das experiências culturais, sociais, econômicas, políticas e ambientais do povo do Semiárido. A relação com a natureza, o armazenamento e uso adequado da água da

\begin{tabular}{|l|l|l|l|l|}
\hline Q Rovista Dialectus & Ano 4 & n. 11 & Agosto - Dezembro 2017 & p. $192-204$ \\
\hline
\end{tabular}


chuva, o manejo da caatinga, o conhecimento sobre os animais e as plantas nativas ou adaptadas à região, são aspectos que interagem neste processo possibilitando a (re)elaboração de alternativas de vida e de vivência de relações sociais, políticas e culturais.

A partir dessas ideias, a elaboração e a execução de políticas públicas voltadas para a convivência com o semiárido, levando em consideração, sobretudo, as questões do desenvolvimento sustentável, da autonomia e da (in)segurança alimentar e nutricional no Alto Sertão Paraibano, por exemplo, engendram relações de saber/poder por meio das quais são negociados os conflitos existentes e as implicações políticas e socioculturais que se interpõem no processo de instituição da ideia de convivência.

O alcance do desenvolvimento sustentável, numa perspectiva de convivência, também inclui a conquista de visibilidade política, a educação e a participação dos setores da sociedade civil nos espaços e nas políticas públicos.

O conceito de desenvolvimento sustentável, enunciado prioritário da ideia de convivência com o semiárido, começou a ser elaborado nas décadas de 1970 e 1980, no contexto de uma grave crise do sistema capitalista mundial. Crise motivada pelo esgotamento de práticas, sobretudo no que diz respeito às relações entre o homem e a natureza. Desse modo, a ciência e a tecnologia que, por quase dois séculos, professaram a inesgotabilidade dos recursos naturais, começaram a ser questionadas pela recorrência de catástrofes planetárias, vislumbradas em horizontes cada vez mais próximos e mais espacialmente distribuídas pelo planeta.

Em 1972 foi realizada, por iniciativa da Organização das Nações Unidas - ONU, a Conferência de Estocolmo, representando a primeira iniciativa de fôlego para o debate das questões ambientais e uma tentativa de estabelecer parâmetros norteadores do desenvolvimento capitalista no planeta.

Dois outros momentos que marcaram este debate foram: a Conferência realizada pela ONU em 1992, no Rio de Janeiro, e, posteriormente, em meados dos anos 1990, a divulgação do Relatório Brundland. Este último, resultado do trabalho da Comissão Mundial da ONU sobre o Meio Ambiente e o Desenvolvimento, parte de uma detalhada análise dos problemas socioeconômicos e ecológicos de uma sociedade em escala global, enfatizando a articulação entre economia, tecnologia, sociedade e política para conceituar desenvolvimento sustentável como:

\begin{tabular}{|l|l|l|l|l|}
\hline Q Rovista Dialectus & Ano 4 & n. 11 & Agosto - Dezembro 2017 & p. $192-204$ \\
\hline
\end{tabular}




\begin{abstract}
Aquele que atende às necessidades do presente sem comprometer a capacidade das gerações futuras também atenderem as suas (...) é um processo de mudança no qual a exploração dos recursos, a orientação dos investimentos, os rumos do desenvolvimento tecnológico e a mudança institucional está de acordo com as necessidades atuais e futuras. (...) é um desenvolvimento que mantém possíveis as opções futuras. (...) é uma correção, uma retomada do crescimento alterando a qualidade do desenvolvimento. (...) é uma mudança no teor do crescimento, a fim de tornálo menos intensivo de matéria-prima e mais eqüitativo em seu impacto (BRUNDLAND, Apud Ribeiro, 2000, p. 157-158).
\end{abstract}

Embora ganhando relevância institucional, nas últimas décadas, a noção de desenvolvimento sustentável ainda continua marcada pela polissemia que envolve o próprio termo "desenvolvimento". Deste modo, além desse enunciado ser apropriado por segmentos das mais variadas tendências e credos políticos e ideológicos, a ideia de desenvolvimento sustentável tem sido relativamente mais utilizada, defendida e difusamente definida por setores como ONGs, órgãos governamentais, agências multilaterais e empresários que transitam mais ativamente neste território. $\mathrm{Na}$ arena das ciências sociais uma definição mais precisa e consensual sobre a questão ainda não está elaborada de forma sistemática.

A discussão sobre as disparidades nas relações e no exercício do poder, no contexto do desenvolvimento sustentável, aponta na direção de outro aspecto que não recebe a devida atenção quando entra em pauta a questão de qual a melhor forma de organização e administração do Estado e quais os atores sociais que entram em cena neste processo. Nesta direção, os atores sociais, que também seriam móveis do desenvolvimento sustentável, seriam ampliados com a incorporação da incontável gama de excluídos, marginalizados, interditados, sem terra, sem teto, sem comida e sem água que o modelo de desenvolvimento capitalista, considerado como excludente e elitista, produziu nos últimos séculos. Essa inserção, contudo, não pode descuidar de um aspecto ofuscado pelo discurso salvífico da sustentabilidade: o da pluralidade e diversidade de sujeitos e situações sociais que compõem o intricado mosaico de regiões, de países e do planeta.

Também é imperativo que o debate sobre autonomia seja considerado como outro enunciado que subsidia a discussão do grau e das formas de "integração dos excluídos" às relações econômicas, socioculturais e de poder.

\begin{tabular}{|l|l|l|l|l|}
\hline Qovista Oialectus & Ano 4 & n. 11 & Agosto - Dezembro 2017 & p. $192-204$ \\
\hline
\end{tabular}


Urge perceber que a questão primordial imposta no cerne dessa nova discussão, e que imprime o sentido da convivência é, pois, a preservação da vida humana e da natureza e a contribuição que ambas podem dar uma à outra, promovendo melhorias nas condições sociais e de desenvolvimento econômico à região do Semiárido, facilitando o acesso à água e à terra para o uso humano e geração de renda.

Pensar a convivência com o semiárido dentro desse novo diálogo, que insurge como proposta de ruptura ao discurso do combate à seca e às relações de dominação e dependência $^{4}$, não significa, portanto, travar uma luta incansável contra a natureza à custa da defesa de interesses próprios isolados da coletividade, mas buscar constantemente estar em plena harmonia com ela, numa relação íntima e sustentável ${ }^{5}$, e que seja promotora do desenvolvimento humano. Considerar que homem, mulher e meio precisam estar enredados de forma equilibrada implica em estabelecer uma relação de interdependência entre eles, ou seja, pensar que um precisa do outro. E vivenciar esta relação em harmonia é um grande passo para desvelar o segredo da convivência.

Desse modo, mais do que introduzir novos conceitos e ensejar novas percepções sobre o que é ser semiárido trata-se de desconstruir uma linguagem discursiva que acaba gerando imagens negativas da região e fomentando o conformismo social nas pessoas. Uma das funções da linguagem, segundo Lane (2008, p. 14).

(...) é a mediação ideológica inerente nos significados das palavras, [que institui] (...) o poder de pensar e 'conhecer' a realidade, explicando-a através de verdades inquestionáveis e atribuindo valores absolutos de tal forma que contradições geradas pela dominação e vividas no cotidiano dos homens são camufladas e escamoteadas por explicações tidas como verdades 'universais' ou 'naturais', ou, simplesmente, como 'imperativos categóricos' em termos de 'é assim que deve ser', 'sempre foi assim' e 'assim será'.

\footnotetext{
${ }^{4}$ A ideia de que as relações de poder se caracterizam como relações de dominação e dependência sempre esteve presente na história do Brasil servindo como enunciado para viabilizar o enriquecimento e a manutenção de privilégios de uma minoria, em detrimento da exploração desenfreada da maioria da população. Para a elite dominante que detinha prestígio e participação junto ao poder político, beneficiando-se dos recursos financeiros destinados às obras de combate à seca, nunca interessou que as famílias que dependiam de seu apoio se tornassem autônomas (Cf: ÁGUA DE CHUVA: O segredo da convivência com o Semiárido Brasileiro, 2001, p.14-15). É preciso ter em vista que "as relações de poder em uma sociedade como a nossa produzem sempre a censura, de tal modo que há sempre silêncio acompanhando as palavras" (Cf. ORLANDI, 2005, p.83). Talvez isso explique a posição das pessoas que se submetiam a esta relação desigual.

${ }^{5}$ A noção de sustentabilidade aqui pressupõe "fortalecimento e melhoria das relações humanas, e destas com o meio em que vivem...". (SOUSA, 2005, p.46).
}

\begin{tabular}{|c|c|c|c|c|}
\hline Rovista Qialectus & Ano 4 & n. 11 & Agosto - Dezembro 2017 & p. $192-204$ \\
\hline
\end{tabular}


De acordo com essa compreensão, vimos aprofundando o debate e a troca de experiências entre os diversos setores da sociedade civil e as múltiplas forças sociais, políticas e culturais presentes no Alto Sertão Paraibano, problematizando a organização e a participação política de habitantes deste espaço, a importância de seu protagonismo para a elaboração e a execução de políticas públicas que repercutam na melhoria de condições de vida e de trabalho e na construção de novos saberes e de novas práticas. Isso implica o repensar das formas de produção e a (re)definição de fazeres e dizeres do e sobre o Semiárido, avaliando a inserção do enunciado da convivência a partir de uma lógica que considere sua pluralidade e sua diversidade identitária.

O discurso da convivência se anuncia, nessa perspectiva, como elemento fundante de uma prática política que envolve todas as dimensões da vida e das experiências culturais, sociais, econômicas, políticas e ambientais dos povos do Semiárido. A relação com a natureza, o armazenamento e uso adequado da água da chuva, o manejo da caatinga, o conhecimento sobre os animais e as plantas nativas ou adaptadas à região são aspectos que interagem neste processo possibilitando a (re)elaboração de alternativas de vida e de vivência de relações sociais e políticas.

O alcance do desenvolvimento sustentável, na perspectiva do discurso da convivência, também inclui a educação e a participação dos setores da sociedade civil nos espaços e nas políticas públicos. A sustentabilidade e a convivência, portanto, devem ser consideradas como fundamentos dos programas e ações sociais interessados na melhoria das condições socioeconômicas da região. No entanto, tal visibilidade depende das táticas e estratégias que envolvem certas exigências e que se situam entre práticas discursivas e culturais, por meio de uma tessitura entre léxico e experiência pautados em relações de poder e saber mutuamente implicadas.

[...] certamente os discursos são feitos de signos; mas o que fazem é mais que utilizar esses signos para designar coisas. É esse mais que os torna irredutíveis à língua e ao ato da fala . É esse "mais" que é preciso fazer aparecer e que é preciso descrever. (FOUCAULT, 2015, p. 60).

Falar de convivência com o semiárido implica, pois, considerar as condições históricas para instituição desse objeto discursivo como um conjunto de enunciados que potencializam saberes sobre o ser semiárido e relaciona-os com outros objetos, que são forjados na mesma formação discursiva por meio de uma historicidade. Enuncia-se,

\begin{tabular}{|l|l|l|l|l|}
\hline Q Rovista Dialectus & Ano 4 & n. 11 & Agosto - Dezembro 2017 & p. $192-204$ \\
\hline
\end{tabular}


assim, um campo discursivo perpassado por ditos, escritos, corpus e vivências sociais imbricados em relações de poder/saber.

Neste sentido, Foucault nos adverte que a noção de discurso deve ser compreendida como:

Um conjunto de regras anônimas, históricas sempre determinadas no tempo espaço, que definiram em uma dada época, e para uma área social, econômica, geográfica, ou linguística dada, as condições de exercício da função enunciativa. (FOUCAULT, 2015, p. 43).

Assim sendo, a compreensão da convivência explicita como os discursos são articulados a partir das posições e dos lugares que os sujeitos ocupam, o que empresta legitimidade e reconhecimento às suas falas, as quais permitem apreender como o deslocamento de compreensões acontece a partir da legitimação de novos discursos. Nestes termos, o discurso da convivência com o semiárido começa a se instituir no imaginário sertanejo suplantando a compreensão prevalecente, até algumas décadas, quando as pessoas pensavam que seria possível acabar com a seca, não dando relevância ao fato de ela ser um fenômeno climático natural. Isso implica dizer que a idéia de convivência com o semiárido está imbricada por uma relação de aprendizagem, ou seja, aprender a respeitar o meio em que se vive, estabelecendo estratégias de sobrevivência. (MOREIRA NETO; LIRA, 2015).

Portanto, no que concerne à luta pela concretização do projeto de convivência, não se trata apenas de negar as concepções passadas - que ainda pairam sobre o tempo presente (a exemplo da ideia de combate à seca) - por meio da instituição de novos saberes e dizeres sobre o Semiárido Brasileiro, mas de se impor, não como fronteira e sim como horizonte, como caminho alternativo e mais viável, como discurso eminente dentro da sociedade.

A mudança de discurso que se percebe com o redirecionamento de concepções para a promoção da cultura de convivência confirma claramente a afirmação de Foucault, de que: “[...] o discurso não é simplesmente aquilo que traduz as lutas ou os sistemas de dominação, mas aquilo por que, pelo que se luta, o poder do qual nos queremos apoderar." (FOUCAULT: 1999, p.10). Assim sendo, em todo tempo existem aqueles - sejam pessoas sejam instituições - que efetivamente sustentam o discurso e cujas palavras incidem com mais força sobre as outras pessoas a ponto de se tornarem um ideal coletivo ou uma nova regra em meio às regras já existentes. Por isso, é

\begin{tabular}{|l|l|l|l|l|}
\hline Q Rovista Dialectus & Ano 4 & n. 11 & Agosto - Dezembro 2017 & p. $192-204$ \\
\hline
\end{tabular}


importante que se perceba o que está para além do que fora dito, as intenções que as palavras carregam consigo, os sentimentos que elas suscitam nas pessoas, o embate entre o real e o simbólico ${ }^{6}$. Afinal, as palavras valem por aquilo que elas representam dentro de uma determinada realidade.

A contribuição de Foucault para esta problematização se dá, pois, no sentido de que o Semiárido, assim como os sujeitos que o habitam, devem ser pensados como efeitos das construções discursivas, ao invés de serem tomados como ponto de partida para as práticas sociais. Assim, por exemplo, o nível de inferência das políticas públicas, da educação contextualizada e do protagonismo político e social dos habitantes do Semiárido, possui uma relação direta com os enunciados que instituem a ideia de convivência.

Um dos elementos que podem estabelecer uma compreensão dessa complexidade refere-se à inserção dos setores populares nas esferas de decisão, que, se por um lado, é colocada como um pressuposto para a satisfatória execução das políticas públicas, alterando a "engenharia institucional" e a correlação de forças entre os atores envolvidos e favorecendo resistências, conflitos e pressões nos processos de elaboração, execução, gestão e controle das políticas públicas, por outro lado, a experiência revela que a vivência de novas relações de poder só se registra onde há o controle social, o qual traz estreita relação com a ideia da constituição de uma esfera pública democrática que possibilite o exercício de novas relações entre a sociedade e o governo.

\begin{abstract}
A ideia básica reside na possibilidade dos grupos organizados influírem e decidirem sobre o tipo de sociedade e de ação governamental necessários ao bem estar da coletividade, além de manter mecanismos de avaliação das ações governamentais. Isso supõe a institucionalização de instrumentos de controle do setor público pela sociedade, garantindo, (...) a fiscalização não somente da parte do orçamento (...), mas também a definição de prioridades e estratégias de ação, a localização de serviços, etc. (ANDRADE, 2004, p. 234).
\end{abstract}

O controle social aparece, portanto, como mudança da postura autoritária, herança de uma história marcada pelos desmandos políticos, sinalizando para práticas institucionais deliberativas e de maior representatividade da população. A ideia é de que o Estado, ao ceder espaço para segmentos populares, permite uma forma de participação pública ampliada.

\begin{tabular}{l}
\hline${ }^{6}$ Cf. ORLANDI, 2005, p. 18. \\
\begin{tabular}{|c|c|c|c|c|}
\hline QRovista Dialectus & Ano 4 & n. 11 & Agosto - Dezembro 2017 & p. $192-204$ \\
\hline
\end{tabular}
\end{tabular}


No debate acerca das questões supracitadas, enuncia-se que o processo de utilização desse espaço tem sido limitado pela precariedade do movimento associativista, a resistência dos setores organizados e a interferência de interesses político-partidários no interior dos fóruns institucionalmente constituídos para a elaboração das políticas públicas, barrando a dinamização dos mesmos.

No propósito de promover as mudanças necessárias e mais urgentes da região semiárida, seja no âmbito político, econômico e social, seja no campo das relações de poder/saber existentes, as organizações gestoras de políticas públicas direcionadas ao desenvolvimento do Semiárido Brasileiro (SAB) se incumbem de abrir caminhos para positivar soluções para os impasses relacionados à qualidade de vida nessa região, por meio de programas de convivência viáveis e sustentáveis.

As tensões e contradições constituintes do desenvolvimento das formas de compreender tais questões se apresentam como possibilidades de mudança, desde que trabalhadas de forma sistemática, considerando que as relações discursivas são elaboradas como modos de dizer e fazer que não estão externas ou internas ao discurso, mas estão no "limite do discurso", portanto,

(...) oferecem-lhes objetos de que ele pode falar, ou antes (...) determinam o feixe de relações que o discurso deve efetuar para poder falar de tais ou tais objetos, para poder abordá-los, nomeá-los, analisá-los, classificá-los, explicálos etc. Essas relações caracterizam não a língua que o discurso utiliza, não as circunstâncias em que ele se desenvolve, mas o próprio discurso enquanto prática. (FOUCAULT: 2015, p.56).

Nestes termos, a proposta de convivência com o semiárido se apresenta como possibilidade de uma nova elaboração deste espaço tendo como enunciados básicos a adaptação $^{7}$, a promoção da cidadania e a aquisição da autonomia para esse povo, através do gerenciamento dos recursos naturais existentes, sobretudo os hídricos, tendo a educação uma relevância impar na reelaboração da compreensão do que é viver no Semiárido.

Portanto, o discurso da convivência com o semiárido pode ganhar significância quando práticas como as que foram citadas acima começam a inferir sobre as questões sociais dessa região elaborando alternativas capazes de amenizar alguns dos seus problemas, possibilitando a formação de uma consciência mínima da capacidade que os

\begin{tabular}{l}
\hline${ }^{7}$ Cf. MALVEZZI, 2007, p.11-12. \\
\begin{tabular}{|c|c|c|c|c|}
\hline Gerista Dialectus & Ano 4 & n. 11 & Agosto - Dezembro 2017 & p. $192-204$ \\
\hline
\end{tabular}
\end{tabular}


habitantes dessa região têm de transformar o seu contexto social, ou seja se positivando de modo a instituir e legitimar um discurso de autoridade sobre a convivência. Apreender os nexos, as afinidades e dissonâncias, as resistências e táticas que se insinuam e se camuflam nesta formação discursiva emerge como ponto norteador da reflexão sobre estas questões.

\section{Conclusão(ões)}

No percurso genealógico que temos traçado foi possível perceber como o discurso da convivência é apropriado e reelaborado a partir dos interesses e das intencionalidades históricas que marcam os ditos e escritos que dão subsídio à compreensão do que é ser semiárido e auxiliam na percepção de que essa região apresenta estratégias de convivência e basta saber lidar com elas.

Nesse sentido, as análises permitem, por exemplo, certo entendimento de como as políticas públicas que têm sido elaboradas para o Semiárido, com vistas à convivência e ao desenvolvimento sustentável, sobretudo para o campo, consideram os diferenciais de poder/saber que definem a participação nas tomadas de decisões e na implementação dessas políticas e problematizam o processo de produção e socialização de conhecimentos e saberes no Alto Sertão Paraibano; bem como, contribuem efetivamente para a convivência e a sustentabilidade nessa região.

Portanto, o arcabouço conceitual que abriga a definição de desenvolvimento sustentável envolve um intrincado contexto de tensões e disputas que perpassa diversos discursos - políticos, acadêmicos, socioculturais etc. - do que concerne a definição do que é sustentabilidade, à nomeação de quais são os sujeitos sociais deste desenvolvimento e à(s) forma(s) de organização econômica e social que se afina(m) com esta proposta. Múltiplas posturas se perfilam neste debate. Cada uma traz, nas entrelinhas: enunciados, posições ideológicas e concepções de mundo específicos.

Os discursos veiculados nos documentos, nas falas, em atos, comportamentos, dizeres e procederes observados e investigados são compreendidos como uma prática que provém da formação de saberes, como um espaço em que poder e saber se articulam para construir subjetivações socioculturais e criar identidades. Os nexos, as afinidades e dissonâncias, as resistências e táticas, que se insinuam e se camuflam na formação discursiva da "convivência com o semiárido", emergem como relações discursivas que

\begin{tabular}{|l|l|l|l|l|}
\hline Govista Cialectus & Ano 4 & n. 11 & Agosto - Dezembro 2017 & p. $192-204$ \\
\hline
\end{tabular}


são elaboradas como modos de dizer e fazer. Relações discursivas que não estão externas ou internas ao discurso, mas estão no "limite do discurso".

A investigação sobre como se institui e se operacionaliza o discurso da convivência com o semiárido tematizada e problematizada como prática que, extrapolando a fronteira material de entidades, associações, documentos, elabora um campo discursivo marcado por disputas e barganhas que se expressam em relações de poder assimétricas e instituídas a partir de uma visão da convivência entendida e vivenciada mais como reprodutora de saberes e conhecimentos que, também, em momentos tantos, se configuram alheios e estrangeiros ao mundo e às elaborações discursivas de gentes do semiárido. Dessa forma, os discursos que se instituem e se legitimam em enunciados como convivência com o semiárido, educação contextualizada, políticas públicas, não devem perder a trilha apontada por Foucault (2015) quando enfatiza e recomenda que

(...) analisando os próprios discursos, vemos se desfazerem os laços aparentemente tão fortes entre as palavras e as coisas, e destacar-se um conjunto de regras, próprias da prática discursiva. Essas regras definem não a existência muda de uma realidade, não o uso canônico de um vocabulário, mas o regime dos objetos. "As palavras e as coisas" é o título - sério - de um problema; é o título - irônico - do trabalho que lhe modifica a forma, lhe desloca os dados e revela, afinal de contas, uma tarefa inteiramente diferente, que consiste em não mais tratar os discursos como conjuntos de signos (elementos significantes que remetem a conteúdos ou a representações), mas como práticas que formam sistematicamente os objetos de que falam. (FOUCAULT, 2015, p.59-60)

Enfim, assume relevância o fato de entender a convivência com o semiárido como uma questão que traz implícitas relações de poder-saber que operam transformações nos discursos e nas formas de ver e dizer a realidade e também estão presentes no cotidiano das relações sociais marcadas pela dinamicidade das mudanças sociais, políticas e culturais. Ou seja, o discurso da convivência é uma ideia elaborada a partir de uma intencionalidade discursiva, perpassada por uma diversidade de abordagens. Ela sofre as tensões, distensões e contradições de sua operacionalização e, embora seus enunciados apresentem as possibilidades de se conviver no Semiárido sem agredi-lo, embora se institua como "discurso de autoridade" não se legitima de forma totalizante e/ou unificadora. Elaborações teóricas também mostram a complexidade que existe entre os habitantes dessa localidade, defendendo que conviver não apenas se resume às pessoas que habitam esse espaço, mas abrange todo um contexto político,

\begin{tabular}{|l|l|l|l|l|}
\hline Q Rovista Dialectus & Ano 4 & n. 11 & Agosto - Dezembro 2017 & p. $192-204$ \\
\hline
\end{tabular}


cultural, social e econômico, sobretudo quando se considera o Semiárido Brasileiro como um território complexo e versátil e que, nesta complexidade habita e convive uma polissemia de ideias e discursos por meio da qual fissuras e brechas podem ser reveladas.

\section{REFERÊNCIAS}

Água de chuva: o segredo da convivência com o Semi-Árido Brasileiro. Cáritas Brasileiras/Comissão Pastoral da Terra/Fian-Brasil. São Paulo: Paulinas, 2001.

ANDRADE, Ilza Araújo Leão de. Conselhos de Desenvolvimento Rural: um espaço adequado para pensar o desenvolvimento local? In. SCHNEIDER, S.; SILVA, M. K.; MARQUES, P. E. M.; CAZELLA, A. A. Políticas Públicas e participação social no Brasil rural. Porto Alegre: Editora da UFRGS, 2004, p. 233-250.

CARVALHO, L. D. A emergência da lógica da "Convivência com o Semi-Árido" e a construção de uma nova territorialidade. In. Educação para a convivência com o semiárido: Reflexões teórico-práticas. Juazeiro: Secretária Executiva da RESAB. 2004, p. 13-28.

FÓRUM NORDESTE. Ações Permanentes para o desenvolvimento do Nordeste Semiárido brasileiro: propostas da sociedade civil. Recife, 1993.

FOUCAULT, Michel. A Arqueologia do Saber. Rio de Janeiro: Forense Universitária, 2015 .

A ordem do discurso. São Paulo, Loyola, 1999.

LANE, S. T. M. e CODO, W. Psicologia social e o homem em movimento. São Paulo: Brasiliense, 1994.

LIRA, Maria Thaize dos Ramos, MOREIRA NETO, Mariana. Relatório Final: Discursos sobre convivência com o semiárido: invenções e dispersões. UFCG/PIBIC/CNPq. Vigência 2010/2013.

MALVEZZI, Roberto. Semiárido: uma visão holística. 1. ed. Brasília: Confea, 2007.

ORLANDI, Eni Puccinelli. Análise de discurso: princípios e procedimentos. 6.ed. Campinas/São Paulo: Pontes, 2005.

RIBEIRO, Gustavo Lins. Cultura e política no mundo contemporâneo. Brasília: Editora Universidade de Brasília, 2000.

SOUZA, Ivânia Paula Freitas de. A gestão do currículo escolar para o desenvolvimento humano sustentável do Semi-Árido Brasileiro. São Paulo: Peiróplois, 2005.

\begin{tabular}{|l|l|l|l|l|}
\hline Q Povista Qialectus & Ano 4 & n. 11 & Agosto - Dezembro 2017 & p. $192-204$ \\
\hline
\end{tabular}

